\title{
Sleep deprivation does not affect spatial memory in rats
}

\author{
ANTHONY M. DODGE and WILLIAM W. BEATTY \\ North Dakota State University, Fargo, North Dakota 58105
}

\begin{abstract}
The effect of sleep deprivation on working memory for spatial information was evaluated. Rats were trained on a win-shift strategy in an eight-arm maze until they exhibited accurate retention when an 8-h delay was imposed between the fourth and fifth choices. Then the effects on spatial memory of depriving the rats of sleep throughout the retention interval were compared with the influence of a stress control (swimming for $1 \mathrm{~h}$ during the retention interval) or no treatment, using a counterbalanced within-subjects design. Although sleep deprivation produced a marginally significant impairment in spatial memory at a 4-h delay, in two replications at an 8-h delay interval there was no suggestion of an effect of sleep deprivation. Thus, spatial memory in the radial maze remains intact after brief periods of sleep deprivation. The present findings are consistent with other recent studies, all of which demonstrate the remarkable resistance to disruption by retroactive treatments of the rat's spatial memory system.
\end{abstract}

Recent research has demonstrated that rats possess an excellent memory for spatial locations. When trained on a win-shift strategy in an eight-arm maze, most animals quickly learn to visit each arm only once and maintain nearly perfect performance thereafter. The task is readily converted into a test of spatial working memory by imposing a delay between the fourth and fifth choices. Using this approach, Beatty and Shavalia (1980) demonstrated that rat spatial memory is extremely long-lived. Choice accuracy on Choices 5-8 exceeded $90 \%$ correct for delays as long as $4 \mathrm{~h}$ and remained above chance for delays of up to $12 \mathrm{~h}$.

Another property of spatial working memory in the rat is resistance to retroactive interference. Using brief delays, Maki, Brokofsky, and Berg (1979) exposed rats to various visual, auditory, kinesthetic, and olfactory stimuli during the retention interval. None of these treatments affected spatial memory. Using 4-h delays, Beatty and Shavalia (in press) found that testing rats in a second eight-arm maze did not affect their memory for the first maze, even if conditions were arranged so that the rats had to remember spatial information from both mazes simultaneously.

Recently, there has been a renewal of interest in the relationship of sleep, especially REM sleep, to memory. Following new learning, the amount of time spent in REM sleep is often increased (see Pearlman, 1979, for a review), and as little as $2 \mathrm{~h}$ of REM sleep deprivation immediately after training can impair retention (Pearlman \& Becker, 1973; Pearlman \& Greenberg, 1973). In the present experiment, we examined the effect of sleep deprivation on spatial working memory.

\section{METHOD}

Subjects

The subjects were 12 male albino rats born in the laboratory to mothers purchased from the Holtzman Company, Madison, Wisconsin. Prior to the present experiment, they had served as subjects in an experiment on social play, which is described in another report (Panksepp \& Beatty, in press). Throughout the present study, the rats were caged singly in standard laboratory cages with free access to water in an air conditioned animal room $\left(23^{\circ} \mathrm{C} \pm 2^{\circ} \mathrm{C}\right)$ that was illuminated from 0800 to 2200 . Behavioral tests occurred during the light portion of the daynight cycle.

\section{Apparatus}

The eight-arm maze was highly similar to the one used by Maki et al. (1979), except for the addition of black plastic sidewalls $(3.5 \mathrm{~cm}$ high) extending the length of each arm. The room housing the maze was illuminated by a single $40-\mathrm{W}$ bulb suspended directly above the center hub of the maze. The room contained relay racks, shuttleboxes, a table, a chair, a filing cabinet, and other miscellaneous equipment.

\section{Procedure}

At about 70 days of age, the rats were placed on a restricted feeding schedule designed to maintain body weight at $85 \%$ of free-feeding level. To allow for growth, the rats were permitted to gain $5 \mathrm{~g} /$ week throughout the experiment.

During pretraining, the rats were first habituated to the apparatus until they visited each arm and consumed food from the foodwell within $15 \mathrm{~min}$. Then training began at the zerodelay condition. At the outset of the session, a single 190-mg Noyes pellet was placed into the food well at the end of each alley. The food was not replenished, so the optimal strategy was to visit each arm only once. Training continued until each rat visited seven different arms out the the first 8 choices and all eight arms in the first 10 choices for 10 consecutive days. Delay training began by confining the rat in the central hub of the maze for $1 \mathrm{~min}$ between Choices 4 and 5. The delay interval was gradually incremented to $8 \mathrm{~h}$ over a period of 1.5 months. All delays longer than 1 min were imposed by returning the animal to its home cage. By the end of pretraining, all animals maintained $75 \%-85 \%$ correct on Choices 5-8 at the 8-h delay.

After 10 days of retraining at the 4-h delay condition, the sleep-deprivation phase began. Each rat received 3 tests each under sleep deprivation (SD) or swim control (SW) and 12 tests under the control (C) condition. For the SD condition, the rat was placed onto an inverted clay flower pot $(7.5-\mathrm{cm}$ diam at the 
base) that was set into a plastic laundry tub (46-cm diam) filled to a depth of $11 \mathrm{~cm}(1 \mathrm{~cm}$ below the base of the flower pot) with tap water. The animal remained in this condition for the duration of the delay interval. In the SW condition, the flower pot was removed and the rat was simply placed into the water for $1 \mathrm{~h}$, starting $2 \mathrm{~h}$ after the first four choices. In the $\mathrm{C}$ condition, the rat spent the entire retention interval in its home cage. The order of SD and SW treatments was counterbalanced. The flower pot technique, as employed here, has been shown to produce relatively selective deprivation of REM sleep (see Morgane, Stern, \& Bronzino, 1977). The SW procedure was devised to control for the stressful effects of confinement on the flower pot and has little effect on total sleep time (Mendelson, Guthrie, Frederick, \& Wyatt, 1974). But since we did not monitor EEG on our subjects, we prefer to describe our manipulation as sleep deprivation.

As the results of the tests at the 4-h interval suggested a marginal effect of SD on spatial memory, the rats were retrained at an 8-h delay for about 10 days. The nine most consistent subjects were selected for this test, and each animal received two tests under the SD and SW conditions and eight tests under the C condition, counterbalanced as before. The SD treatment was in effect for the duration of the 8-h delay interval, and the SW condition began $2 \mathrm{~h}$ after Choice 4 and lasted $1 \mathrm{~h}$. During this test, performance for three of the rats deteriorated to below $65 \%$ correct during the $\mathrm{C}$ condition, making the situation less than optimally sensitive. Accordingly, these three rats were replaced with the other three rats from the 4-h tests; these "new" rats had by this time attained stablc and fairly accurate performance at the 8-h delay. The experiment was replicated with 3 tests each under SD and SW conditions and 12 tests under the $\mathrm{C}$ condition, counterbalanced as described above. In addition, during these tests, the SW condition began $6 \mathrm{~h}$ after Choice 4 , so that the physiological state of the rats at the time of the retention test was more nearly similar for the 4- and 8-h tests.

\section{RESULTS AND DISCUSSION}

Table 1 shows the mean percent correct on Choices 5 8 for each treatment condition during the three separate delay tests. Separate analyses of variance were performed on the data from each delay test. Analysis of the 8-h delay data revealed no reliable effect of treatment (both Fs $<1$ ). On the 4-h test, there was a modest treatment effect $[F(2,22)=3.74, p<.05]$. Subsequent tests indicated that performance under the SD condition was poorer than under $\mathrm{C}$, but the difference between SW and SD was not reliable.

The present findings indicate that working memory for spatial information, as tested in the eight-arm maze, is not readily disrupted by exposure to a sleep-deprivation procedure that is thought to produce relatively selective deprivation of REM sleep. These results are consistent with our earlier failure to observe an effect on spatial memory of treatment with barbiturates during the
Table 1

Mean Percent Correct Choices 5-8

\begin{tabular}{|c|c|c|c|c|c|c|}
\hline \multirow[b]{3}{*}{ Delay } & \multicolumn{6}{|c|}{ Treatment } \\
\hline & \multicolumn{2}{|c|}{$\mathrm{C}$} & \multicolumn{2}{|c|}{ SW } & \multicolumn{2}{|c|}{ SD } \\
\hline & Mean & SEM & Mean & SEM & Mean & SEM \\
\hline 4 & 86.3 & 1.4 & 86.1 & 3.7 & 77.8 & 2.8 \\
\hline $8^{*}$ & 70.2 & 2.8 & 69.8 & 4.2 & 75.1 & 3.6 \\
\hline $8+$ & 86.4 & 3.3 & 83.3 & 5.5 & 83.3 & 4.4 \\
\hline
\end{tabular}

Note-Delay is given in hours. $\quad{ }^{*}$ Replication 1 †Replication 2

retention interval (Beatty \& Shavalia, 1980), since these agents profoundly depress REM sleep (Harvey, 1975). Taken together with other recent results (Beatty \& Shavalia, in press; Maki et al., 1979), these observations provide additional evidence that rat spatial memory is remarkably resistant to disruption by treatments that degrade other forms of memory.

\section{REFERENCES}

Beatty, W. W., \& Shavalia, D. A. Spatial memory in rats: Time course of working memory and effect of anesthetics. Behavioral and Neural Biology, 1980, 28, 454-462.

Be atty, W. W., \& Shavalia, D. A. Rat spatial memory: Resistance to retroactive interference at long retention intervals. Animal Learning \& Behavior, in press.

Harvey, S. C. Hypnotics and sedatives: The barbiturates. In L. S. Goodman \& A. Gilman (Eds.), The pharmacological basis of therapeutics (5th ed.). New York: Macmillan, 1975.

Maki, W. S., Brokofsky, S., \& Berg, B. Spatial memory in rats: Resistance to retroactive interference. Animal Learning \& Behavior, 1979, 7, 25-30.

Mendelson, W. B., Guthrie, R. D., Frederick, G., \& WyATT, R. J. The flower pot technique of rapid eye movement (REM) sleep deprivation. Pharmacology, Biochemistry and Behavior, 1974, 2, 553-556.

Morgane, P. J., Ste rn, W. C., \& Bronzino, J. D. Experimental studies of sleep in animals. In R. D. Myers (Ed.), Methods in psychobiology (Vol. 3). New York: Academic Press, 1977.

PANKSEPP, J., \& BEATTY, W. W. Social deprivation and play in rats. Behavioral and Neural Biology, in press.

Pearlman, C. A. REM sleep and information processing: Evidence from animal studies. Neuroscience and Biobehavioral Reviews, 1979, 3, 57-68.

Pearlman, C. A., \& Becker, M. Brief posttrial REM sleep deprivation impairs discrimination learning in rats. Physiological Psychology, 1973, 1, 373-376.

Pearlman, C. A., \& Greenberg, R. Posttrial ReM sleep: A critical period for consolidation of shuttlebox avoidance. Animal Learning \& Behavior, 1973, 1, 49-51.

(Received for publication October 16, 1980.) 